\title{
LA MIRADA DEL FILÓSOFO Y LA MIRADA DEL HISTORIADOR. LAS REFLEXIONES DE HUME SOBRE LA REFORMA PROTESTANTE*
}

\author{
POR \\ GERARDO LÓPEZ SASTRE ${ }^{1}$ \\ Universidad de Castilla-La Mancha
}

\begin{abstract}
RESUMEN
Para Hume no pueden demostrarse ni la existencia de Dios ni la inmortalidad del alma. Las creencias religiosas son, por tanto, irracionales; pero en tanto que operan en muchas sociedades hay que estudiar qué efectos producen. En el caso de la Reforma protestante dio pábulo a los proyectos políticos más descabellados, pero también desarrolló un ideal de libertad. Sentados estos puntos, analizaremos las propuestas políticas que Hume pensaba que podían obtenerse de este análisis histórico con vistas a minimizar los males sociales que las religiones provocaban.
\end{abstract}

PALABRAS CLAVE: David Hume; Religión; superstición; entusiasmo; protestantismo.

\section{THE POINT OF VIEW OF THE PHILOSOPHER AND THE POINT OF VIEW OF THE HISTORIAN. HUME'S REFLECTIONS ON THE PROTESTANT REFORMATION}

\begin{abstract}
According to Hume, neither the existence of God nor the immortality of the soul can be demonstrated. Religious beliefs are therefore irrational, but as long as they operate in many societies we must study the effects they produce. The Protestant Reformation lent itself to the most absurd political projects, but also developed an ideal of freedom. After studying these points, we will analyze the political proposals that Hume thought could be obtained from this historical study in order to minimize the social ills produced by religions.
\end{abstract}

KEY WORDS: David Hume; Religion; Superstition; Enthusiasm; Protestantism.

CÓMO CITAR ESTE ARTículo / CITATION: López Sastre, G. 2018. «La mirada del filósofo y la mirada del historiador. Las reflexiones de Hume sobre la Reforma protestante». Hispania Sacra 70, 141: 125-135. https://doi.org/10.3989/hs.2018.012

Recibido/Received 09-05-2017

Aceptado/Accepted 09-06-2017

\section{LA MIRADA DEL FILÓSOFO}

En su Tratado de la naturaleza humana, su primera y más importante obra filosófica, Hume afirmaba: «Las

\footnotetext{
Este trabajo se inscribe dentro del proyecto de investigación «Prismas filosófico-morales de las crisis (Hacia una nueva pedagogía socio-política)». Referencia FFI2013-42935-P. Programa estatal de fomento de la investigación científica y técnica de excelencia. Subprograma estatal de generación de conocimiento. Ministerio de Economía y Competitividad. Por lo demás, este ensayo desarrolla y complementa (en la dirección de investigar la visión de Hume del mundo protestante) planteamientos trabajados previamente en López Sastre 2011a: 173-188; en ibídem 2011b: 304-322; y en ibídem 2012: 139-157.

1 Gerardo.Lopez@uclm.es / ORCID iD: http://orcid.org/00000002-9830-0727
}

historias de los reinos son más interesantes que las historias domésticas; las historias de los grandes imperios, más que las de las pequeñas ciudades y principados, y las historias de las guerras y revoluciones, más que las de la paz y el orden».2 Podemos imaginarnos entonces lo interesante que debía de parecerle a nuestro autor el estudio del nacimiento de las diversas transformaciones que conocemos bajo el nombre colectivo de protestantismo. Era muy consciente de que estaba ante una revolución que formaba parte del nacimiento del mundo moderno, y desde luego había provocado bastantes guerras; por eso ocupará una parte central de su Historia de Inglaterra. Debemos pensar, además, que para

\footnotetext{
2 Hume 2012: Libro I, parte III, sección IV, 531.
} 
Hume la filosofía y la historia, aunque disciplinas distintas, estaban relacionadas. La historia ejemplificaba, y de hecho seguramente volvía más complejas, determinadas tesis generales sobre la naturaleza humana y permitía reflexionar sobre importantes ideas de la filosofía política observando cómo funcionaban.

Lo anterior se aprecia muy bien en el caso de la religión: hay un planteamiento que podemos llamar epistemológico y moral, y desde la perspectiva aportada por el mismo se analiza el comportamiento de la religión en la historia de Europa (y como cabía esperar, especialmente de Inglaterra y Escocia) y se elaboran determinadas propuestas y valoraciones.

Como perspectiva filosófica general que circunscribe su tratamiento de cómo operan las religiones en la historia, Hume está convencido de que las mismas carecen de cualquier tipo de apoyo racional. No sólo no puede probarse la existencia de una divinidad (y por lo tanto debiéramos mantenernos en lo que hoy en día llamaríamos una postura agnóstica); es que seguramente somos seres finitos, cuya vida termina con la muerte del cuerpo. ${ }^{3}$ En su ensayo "Sobre la inmortalidad del alma» Hume expone que: "Los argumentos físicos, a partir de la analogía de la naturaleza, son marcadamente favorables a la mortalidad del alma, y son realmente los únicos argumentos filosóficos que habría que admitir en relación con esta cuestión o, en rigor, con cualquier cuestión de hecho». ${ }^{4} \mathrm{Y}$ a continuación presenta el argumento de que el cuerpo y el alma (es decir, la mente) deben considerarse como dos líneas paralelas:

Cuando dos objetos cualesquiera están tan estrechamente relacionados que toda alteración que hayamos podido observar en uno de ellos va unida a una alteración proporcional en el otro, tendríamos que concluir, según todas las reglas de la analogía, que, cuando se producen alteraciones todavía mayores en el primero, y su total disolución, seguirá una total disolución del segundo. ... La debilidad del cuerpo y de la mente en la infancia son exactamente proporcionales. Y también lo son su vigor en la edad adulta, su simultáneo desorden en la enfermedad, su común decadencia gradual en la vejez. El paso siguiente parece inevitable: su común disolución en la muerte. ${ }^{5}$

Es más, si en este texto se indica que el cuerpo y la mente son dos elementos distintos, aunque con una trayectoria paralela, también podríamos pensar que en realidad son dos maneras distintas de referirnos a una misma realidad: «Todo es común al alma y al cuerpo. Los órganos de una son todos ellos órganos del otro. Por tanto, la existencia de la una debe depender de la existencia del otro». ${ }^{6}$ Ser escéptico no significa aquí, en el tema de si hay o no una vida tras la muerte, mantener un montón de dudas. Es criticar con fuerza una creencia que carece de todo apoyo legítimo. Diríamos que la postura de cualquier persona que adecúe sus creencias al grado de evidencia que las mismas posean

3 Para un resumen de los argumentos de Hume sobre la carencia de fundamento racional de las creencias religiosas véase López Sastre 1994: 159-177. En inglés el estudio ya clásico es Gaskin 1988; para una introducción más breve puede verse del mismo autor el capítulo «Hume on religion», en Norton 1993: 313-344.

4 Hume 2011: 507.

5 Ídem.

6 Ídem. será aceptar que la única vida que podemos estar seguros de poseer es esta sobre la Tierra. Y a partir de aquí esa persona verá a la religión como algo irracional, como un conjunto de meras fantasías que debieran abandonarse cuanto antes, pues no tienen ningún apoyo en la razón o en la experiencia.

Pero no sólo es que las creencias religiosas sean irracionales, resulta también que sus efectos morales, sociales y políticos resultan normalmente nefastos. En efecto, podría defenderse la utilidad de la religión aun admitiendo que seguramente sea falsa. Este no es un planteamiento inusual en la historia del pensamiento. Pues bien, Hume deja bien claro que es completamente erróneo. Veamos esta discusión con un cierto detalle. El mismo Hume, actuando con un disimulo que la prudencia hacía aconsejable (es decir, no está manifestando sus verdaderas opiniones), y dirigiéndose a un «amigo aficionado a las paradojas escépticas», presenta este argumento en la Investigación sobre el entendimiento humano:

Concluyes que las doctrinas y razonamientos religiosos no pueden tener influencia sobre la vida porque no deben tenerla; y no consideras que los hombres no razonan del mismo modo que tú lo haces, sino sacando muchas consecuencias de la creencia en una Existencia divina, y suponiendo que la Deidad infligirá castigos por los vicios, y concederá recompensas por la virtud, más allá de lo que aparece en el curso ordinario de la naturaleza. Si este su razonamiento es justo o no, no importa. Su influencia sobre sus vidas y conducta será en cualquier caso la misma. $Y$ aquellos que intentan desengañarlos de tales prejuicios pueden, por todo lo que yo sé, ser buenos razonadores, pero no puedo concederles el ser buenos ciudadanos y políticos; puesto que liberan a los hombres de un freno de sus pasiones, haciendo la trasgresión de las leyes de la sociedad, al menos en algún respecto, más fácil y segura. ${ }^{7}$

Y, por su parte, uno de los personajes de los Diálogos sobre la religión natural, Cleantes (quien no representa a Hume), puede defender que:

La religión, aun corrompida, es todavía mejor que la ausencia absoluta de religión. La doctrina de una vida futura constituye una seguridad tan fuerte y tan necesaria para la moral que nunca debemos abandonarla o despreciarla. Porque si las recompensas y los castigos finitos tienen un efecto tan grande como el que diariamente vemos, ¿cuánto más no debemos esperar de unos castigos y unas recompensas infinitas y eternas? ${ }^{8}$

Pero para Hume este argumento no es concluyente en absoluto, ni siquiera en cuanto a su descripción de cómo funciona la creencia en otra vida. Ya conocemos la defensa de Hume de la tesis de que somos seres finitos. A este nivel, si queremos añadir algo más bastará con destacar que hemos observado en numerosas ocasiones (vamos a pensar que tenemos la suerte de vivir en una sociedad justa y no completamente dominada por la corrupción) los

7 Hume 2004: 319. Esta estrategia de ocultamiento es bastante usual en los escritos de Hume. Así, también se encuentra en los Diálogos sobre la religión natural, donde algunas de la retractaciones de Filón en relación a sus críticas anteriores no creemos que debieran tomarse en serio; sobre todo porque son meramente verbales, declarativas, sin que aparezca en la obra ningún argumento que las justifique. De hecho, tienen mucho de irónicas, destinadas a contentar al creyente que busque un apoyo para no dejarse convencer. Véase Carabelli 1972.

8 Hume 1974: 187. 
castigos que en esta vida recaen sobre la conducta malvada; pero hay que destacar que nunca hemos observado - ni conocemos a nadie que lo haya hecho- esas recompensas y castigos eternos que supuestamente distribuye en el más allá una divinidad convertida por el argumento en policía y juez. Diríamos que esto nos justifica en nuestra renuencia a creer en los mismos, incluso si estuviéramos dispuestos a admitir la inmortalidad del alma, cosa que ya sabemos que sería irracional.

Lo anterior es una razón para pensar que el argumento no tiene por qué funcionar, pero es que cuando acudimos a la experiencia (más allá de lo que estemos autorizados o no a creer) vemos que su forma real de operar es muy diferente de como se ha descrito por parte de los defensores de la utilidad de la religión. De hecho, actúa en la mente del creyente de una manera bastante perversa, pues las ideas religiosas generan su propia moralidad, que resulta ser opuesta a la dirección hacia donde apuntan nuestros impulsos morales naturales. Estos últimos nos llevan a buscar lo que resulta útil o inmediatamente agradable para nosotros mismos o para los demás (porque de manera natural somos benevolentes, nos afecta el bienestar de los demás, piensa Hume). Pues bien, la moralidad religiosa va a premiar las conductas inútiles y desagradables, porque sólo a través de las mismas puede distinguirse el creyente de los que carecen de religión y sólo actúan motivados por sus impulsos espontáneos o sus razonamientos. Sólo con la práctica de lo desagradable y lo inútil puede el hombre religioso mostrar la fuerza o la autenticidad de su creencia, porque evidentemente si no la tuviera actuaría de otra forma. Esta es la explicación, dirá Hume en la Investigación sobre los principios de la moral, del «celibato, el ayuno, la penitencia, la mortificación, la negación de sí mismo, la humildad, el silencio, la soledad, y todo el conjunto de virtudes monásticas». Y continúa:

¿Por qué razón son rechazadas en todas partes por los hombres sensatos, sino porque no sirven para nada; ni aumentan la fortuna de un hombre en el mundo, ni le convierten en un miembro más valioso de la sociedad, ni le cualifican para el solaz de la compañía, ni incrementan su poder de disfrutar consigo mismo? Observamos, a la inversa, que van en contra de todos estos fines deseables; embotan el entendimiento y endurecen el corazón; oscurecen la fantasía y agrian el temperamento. Por lo tanto, las transferimos con justicia a la columna opuesta y las colocamos en el catálogo de los vicios; y ninguna superstición tiene la fuerza suficiente entre los hombres de mundo para pervertir completamente estos sentimientos naturales. Un entusiasta melancólico e insensato puede ocupar después de su muerte un lugar en el calendario; pero casi nunca se le admitirá durante su vida en intimidad y sociedad, excepto por aquellos que sean tan delirantes y sombríos como él. ${ }^{9}$

Es así como esa moralidad religiosa subvierte impulsos como la compasión y la benevolencia, alterando los confines naturales del bien y el mal. A modo de ejemplo Hume escribe en su ensayo «De la norma del gusto»:

A la religión católica romana le es esencial inspirar un odio violento hacia todo otro culto, y presentar a todos los paganos, mahometanos $y$ herejes como

\footnotetext{
9 Hume 1991: 142-143.
}

objetos de la ira y la venganza divinas. Tales sentimientos, aunque son en realidad muy reprobables, los fanáticos de esa confesión los consideran virtudes, y los representan en sus tragedias y poemas épicos como una especie de divino heroísmo. ${ }^{10}$

Al fin y al cabo es fácil pensar que si la divinidad utiliza castigos infinitos y eternos (cosa que Hume tenía muy claro que los cristianos aceptaban), estará autorizando a sus devotos para que empleen todo tipo de violencia. Cualquier dolor que los seres humanos causen no puede compararse en magnitud con el sufrimiento que puede infligir la divinidad. Es más, su decisión de hacerlo empleando castigos eternos puede verse como una clase de modelo a imitar (aunque evidentemente, en tanto que seres finitos nunca llegaremos a su nivel) en nuestra relación con otras personas.

La conclusión general que hay que obtener de la reflexión anterior aparece en boca del personaje que representa a Hume en los Diálogos, Filón: «cuando están en juego los intereses de la religión no hay moralidad lo suficientemente fuerte como para detener al fanático entusiasta. El carácter sagrado de la causa santifica cualquier medida que pueda adoptarse para promoverla». ${ }^{11}$ Contestando a las palabras de Cleantes mencionadas hace muy poco, Filón exclamará:

Pero entonces - dijo Filón- si la superstición vulgar es tan saludable para la sociedad ¿cómo es que toda la historia abunda en tantos relatos de sus perniciosas consecuencias sobre los asuntos públicos? Banderías, guerras civiles, persecuciones, gobiernos derrocados, opresión, esclavitud: tales son las nefastas consecuencias que siempre acompañan a su dominio sobre los espíritus de los hombres. Si alguna vez se menciona al espíritu religioso en alguna narración histórica, tenemos la seguridad de encontrarnos en seguida con los pormenores de las miserias que le acompañan. $Y$ ninguna época fue más feliz y más próspera que aquellas en las que nunca se preocuparon ni oyeron hablar de él. ${ }^{12}$

La última parte del texto es bastante concluyente: lo ideal para una sociedad sería que sus miembros se despreocuparan de la religión. Ello contribuiría en mucho a su felicidad y al progreso social. Pero cuando Hume actúa como historiador no encuentra esta verdadera utopía. Como afirma también el mismo texto, las narraciones históricas nos hablan no de esa situación, sino de las guerras, las persecuciones y las desgracias que las creencias religiosas han provocado. Este es el terreno de la Historia de Inglaterra de Hume y de sus reflexiones sobre el protestantismo y sus efectos. ${ }^{13}$

Pero antes de entrar en las mismas tenemos que hablar mínimamente de las dos categorías con las que Hume va a analizar los fenómenos religiosos: la superstición y el entusiasmo. Se trata de las modalidades que adopta la religión según los principios psicológicos que actúan como

10 Hume 2011: 236.

11 Hume 1974: 190 (Diálogos). Hemos modificado ligerísimamente la traducción, pues el original inglés, "enthusiastic zealot», se traduce mejor por «fanático entusiasta» que no por "entusiasmo fanático», que es como aparece en la edición que estamos utilizando.

12 Hume 1974: 187-188.

13 Sabríamos todavía más de sus ideas sobre la Reforma protestante si hubiera llegado a realizar el proyecto que tuvo durante cierto tiempo: escribir "con un espíritu imparcial» una historia de la Iglesia. Véase la carta a su editor, A. Millar, que se encuentra en el «Textual Supplement» de Mossner 1980: 637. 
su causa. Cuando la debilidad, el miedo, y la melancolía nos llevan a temer males que provendrían de un agente ignoto estamos ante la superstición. Cuando la esperanza, el orgullo y la presunción llenan la imaginación de grandes ideas que atribuimos a la inspiración inmediata de un ser divino que nos habría escogido especialmente estamos ante el entusiasmo. Su influencia sobre el gobierno y la sociedad no puede ser más opuesta. Como la superstición se basa en la depresión de ánimo, la persona se verá a sí misma como despreciable, como indigna de acercarse a la presencia divina, y recurrirá de forma natural a otras personas a las que supone más favorecidas por la divinidad: los sacerdotes. La superstición conlleva entonces el poder de la Iglesia y la ausencia de libertad. En «De los partidos en Gran Bretaña» Hume escribe que:

En todas las edades del mundo, los sacerdotes han sido enemigos de la libertad, y es seguro que esta constante conducta suya tiene que basarse en razones establecidas del interés y la ambición. La libertad de pensamiento y la libertad para expresar lo que pensamos resultan siempre fatales para el poder sacerdotal, $y$ para esos engaños piadosos en los que suele basarse. ${ }^{14}$

Por el contrario el entusiasta despreciará el yugo eclesiástico, pues no considerará que necesite ningún intermediario para acercarse a Dios. Se autoconsagrará a sí mismo y defenderá su libertad de hacer lo que quiera en función de ese contacto directo que supuestamente tiene con la divinidad.

Si por una parte tenemos ese contraste entre una postura que favorece el despotismo y otra que hace lo mismo con la independencia y la libertad, Hume observará como segunda conclusión que las religiones que tienen un componente entusiasta importante "son en el momento de su surgimiento, más furibundas y violentas que las que participan de la superstición, pero al poco tiempo se vuelven más amables y tolerantes». ${ }^{15}$ Esta es, a grandes rasgos, la narración que se va a contar en la Historia de Inglaterra: el choque entre la superstición católica y el entusiasmo protestante. A ello se añadirá la moderación posterior del protestantismo. El resultado para Hume es que, vistos sus efectos a medio o largo plazo, el viaje mereció la pena, al menos desde la perspectiva del siglo XVIII y para los que estén dispuestos a considerar esta transición desde un punto de vista meramente secular. $Y$ desde este mismo momento hay que subrayar que en esta historia la razón no jugó un papel importante. De hecho, Hume aprovechará la ocasión para observar que la historia no nos proporciona ningún ejemplo en donde la argumentación haya sido capaz de liberar al pueblo de esa enorme carga de absurdos con que la superstición lo agobia en todas partes. ${ }^{16}$

\section{Hume 2011: 92.}

15 «De la superstición y el entusiasmo», en Hume 2011: 100. Para este ensayo véase Forbes 1975: 214-215; y para su relación con la Historia de Inglaterra, Le Jallé 2008: 351-363.

16 Véase Hume 1983: vol. III, capítulo XXIX, 140. De ahora en adelante, y vista la extensión de esta obra, la citaremos por el número del volumen, del capítulo y de la página o páginas correspondientes. Hay interpretaciones muy diferentes sobre el sentido o la orientación general de la Historia de Hume. Se ha analizado como conservadora, como meramente imparcial, como defensora del absolutismo monárquico, etc. Personalmente me parece bastante convincente el punto de vista con el que simpatiza David Wootton, que la Historia está dominada por el amor de Hume por la libertad, «aunque sería bastante erróneo

\section{LA MIRADA DEL HISTORIADOR}

Si nos adentramos en el estudio del mundo medieval tal y como aparece en la Historia de Inglaterra de Hume, nos aparece ejemplificada su tesis sobre las consecuencias políticas de la superstición: en numerosas ocasiones se destaca la propensión del clero al poder despótico y su continua oposición a todo tipo de libertad; su gusto por los milagros y por todo lo que incrementara la credulidad del pueblo. Una y otra vez el lector descubrirá que la religión ha servido de mero velo que ocultaba el deseo mundano de riquezas y poder, por no hablar de los impedimentos que tradicionalmente puso la Iglesia a la ejecución regular de la justicia, proporcionando refugio en las iglesias a los perseguidos por la misma y oponiéndose a que los magistrados civiles pudieran juzgar a los clérigos. A ello hay que añadir que mediante el establecimiento de los monasterios se alejó de las artes útiles a muchas personas de las clases más bajas, que fueron mantenidas en lo que para Hume eran asilos de ocio e ignorancia. En fin, con cierta ironía podríamos decir que un relato nada edificante. ${ }^{17}$

En todo caso, también es verdad que Hume reconoce excepciones. Así, escribirá que:

Aunque la religión de aquel tiempo [la Edad Media] no puede merecer un nombre mejor que el de superstición, servía para unir a un cuerpo de hombres que tenían un gran dominio sobre el pueblo, y que impedían que se disolviese la comunidad con las facciones y el poder independiente de la nobleza. Y, lo que era todavía más importante, ponía una autoridad muy poderosa en manos de personas que, por su profesión, sentían aversión hacia las armas y la violencia; que con su mediación templaban la disposición general hacia las empresas militares; y que mantenían, aun en medio de los enfrentamientos, esos lazos secretos sin los que es imposible que subsista la sociedad humana. ${ }^{18}$

Y en otros capítulos de la obra Hume escribirá que los privilegios eclesiásticos habían servido durante épocas de barbarie para controlar el despotismo de los reyes, y que la unión de todas las Iglesias occidentales bajo un pontífice supremo facilitaba las relaciones y el comercio entre las naciones. Mientras que, por otra parte, la pompa y el esplendor del culto propios de una institución tan rica no podían dejar de contribuir al fomento de las bellas artes y de la elegancia en el gusto; a lo que habría que añadir el papel de la Iglesia en la conservación de la cultura antigua durante la Edad Media. ${ }^{19}$ A este respecto es excepcionalmente

equiparar libertad, tal como Hume comprendía el término, con democracia». D. Wootton "Hume 'the historian'», en Norton 1993: 296-297, y véanse las obras a las que remite en la notas de estas páginas, especialmente Phillipson 1989. Precisamente porque Hume quería defender la libertad tenía que prevenir a sus lectores de los resultados negativos de sus excesos cuando los vuelos de la imaginación en torno a la libertad no quedaban atemperados por la razón. Adelanto con esto la conclusión a la que apunta toda la lectura de la obra que voy a desarrollar de aquí en adelante. Por lo demás, la importancia de la Historia en el conjunto de los escritos de Hume puede apreciarse muy bien en la última biografía de Hume publicada. Véanse los capítulos 6 y 7 de Harris 2015.

17 Véanse, como meros ejemplos en el volumen I, los capítulos IV (el apartado sobre innovaciones en el gobierno eclesiástico), VI, y el Apéndice II (el apartado sobre la Iglesia).

18 Hume 1983: II, XII, 14. Lo que está entre corchetes es un añadido nuestro.

19 Véase Hume 1983: II, XXIII y XXIX. 
importante para Hume el descubrimiento del Digesto del emperador Justiniano y el hecho de que los eclesiásticos adoptaran inmediatamente "este excelente sistema de jurisprudencia» y difundieran su conocimiento por toda Europa. Los clérigos, «teniendo grandes posesiones que defender, sintieron la necesidad de volcarse al estudio del derecho, y como a menudo sus propiedades se veían en peligro por la violencia de príncipes y barones, se convirtió en su interés reforzar la observancia de reglas generales y equitativas, pues sólo de ellas podían esperar protección ». ${ }^{20}$

Pero frente a estas afirmaciones, él mismo se encarga de matizar en otro lugar que «la desgracia principal era que en algunas ocasiones los prelados actuaban enteramente como barones; empleaban el poder militar en contra de su soberano o de sus vecinos y, por lo tanto, incrementaban a menudo esos desórdenes que era su deber apaciguar $»{ }^{21}$ Luego la imagen general que Hume nos transmite es la del poder amenazante de una institución (la Iglesia) que en el fondo actúa por motivaciones completamente terrenales, que tiene una fuerte propensión al despotismo y que compite con los poderes que podemos llamar seculares. Esto convertía a la Iglesia en una fuente permanente de enfrentamientos. Hay que tener en cuenta que el papa y sus cortesanos eran extranjeros con respecto a la mayoría de las iglesias que gobernaban, y no podían por tanto tener otro objetivo que el saqueo de las provincias con vistas a obtener las mayores ganancias posibles. Como vivían lejos de los países que sometían, poco les refrenaba la vergüenza o el remordimiento al emplear para lucrarse todos los recursos que se les ocurrieran. Hablando del reinado de Enrique III, Hume escribe que Inglaterra, al ser una de las provincias más remotas sometida a la jerarquía romana, igual que una de las más supersticiosas, sufrió cruelmente esta situación. ${ }^{22}$ Todo el contexto explicativo sugiere que lo mismo podría decirse del conjunto de la Edad Media. Luego, concluyendo ya, si quisiéramos resumir su punto de vista general, nada mejor que este texto:

Pocos establecimientos eclesiásticos se han fundado sobre tan malas bases como la Iglesia de Roma, o se han visto acompañados de circunstancias más perjudiciales para la paz y la felicidad de la humanidad. / Las grandes rentas, privilegios, inmunidades y poderes del clero les convertían en un poder formidable frente al magistrado civil, y armaban con una autoridad demasiado extensa a una clase de hombres siempre estrechamente unidos y a los que nunca falta un pretexto plausible para sus usurpaciones... La cabeza suprema de la Iglesia era un potentado extranjero guiado por intereses, siempre diferentes a los de la comunidad, y en ocasiones directamente contrarios; y como la jerarquía por necesidad anhelaba preservar una unidad de fe, ritos y ceremonias, toda libertad de pensamiento corría un enorme riesgo de extinguirse, y violentas persecuciones - o lo que es peor, una abyecta y estúpida credulidadcundían por todas partes. ${ }^{23}$

Por todos estos males debemos comprender, sostiene Hume, que antes de la Reforma todos los hombres sensatos y virtuosos desearan con impaciencia algún suceso que pudiera reprimir el poder excesivo que el clero poseía en toda

\footnotetext{
20 Hume 1983: II, XXIII, 520

21 Ibídem: I, VII, 286.

Véase ibídem: II, XII, 4.

23 Ibídem: III, XXIX, 136.
}

Europa y que pusiera fin a las pretensiones y usurpaciones sin límites del pontífice romano. Pero, por mucho que el balance del mal prevaleciera en la Iglesia romana, esta no fue la causa principal que produjo la Reforma: «una concurrencia de incidentes debe haber contribuido a producir esa gran obra». ${ }^{24} \mathrm{Al}$ fin y al cabo, podemos pensar - aunque Hume obviamente no lo dice en su Historiaque si la razón hubiera sido una fuerza predominante, los hombres del momento no hubieran dejado de ser católicos para convertirse en protestantes. Simplemente se hubieran vuelto agnósticos y se hubieran despreocupado de la promesa bien poco razonable de una vida más allá de la muerte. La religión habría desaparecido. Excluida la razón como motor de la Historia quedan los intereses mundanos, por mucho que pudieran verse favorecidos por el desarrollo de la imprenta y el aumento del saber. Estos fueron medios que despertaron el afán de novedades y que permitieron la propagación de lo que Hume consideraba la elocuencia ruda y declamatoria de Lutero y sus seguidores. El escándalo de la venta de indulgencias estaba ahí, pero no hubiera producido sucesos importantes si Lutero no hubiera tenido la capacidad de aprovechar el incidente. Pero - continúa Hume su narración- cuando Lutero promulgó sus doctrinas fue fácil alarmarse ante lo radical del remedio, y se previó fácilmente, a partir del celo ofensivo de los reformadores y del defensivo de la Iglesia, que toda la cristiandad iba a entrar en una época de efervescencia y enfrentamientos. En el estado de ignorancia en que, siempre de acuerdo con Hume, Europa estaba sumida durante la Edad Media, la adhesión a la superstición, aunque se mantuviera sin reservas, no era extrema. Igual que en el caso de la idolatría pagana de la Antigüedad, la religión popular consistía más en observancias y prácticas externas que en la posesión de principios que dominaran el corazón o influyeran en la conducta. Podría haberse esperado que el desarrollo del saber y de la preocupación por el conocimiento, creciendo de forma gradual, como en la Antigüedad en Grecia, abriera los ojos de los hombres y corregiría los abusos eclesiásticos más notorios y agobiantes. De hecho, algo de esto se dio en Italia durante lo que Hume llama «el renacimiento de las letras». Pero ese espíritu renacentista duró poco. No debiera sorprendernos, porque ya sabemos de la debilidad de la razón en la Historia. En todo caso, cuando los reformadores "fanáticos y enfurecidos» se levantaron en armas contra la jerarquía papal, y amenazaron con desposeer de forma inmediata a la Iglesia de todas sus riquezas y autoridad, no hay que sorprenderse de que esta se viera dominada por un celo igual en la defensa de sus posesiones. Empezaba así para Europa una época de disturbios, asesinatos y masacres. Una época en la que cuando Hume quiera buscar un símbolo representativo lo encontrará por el lado católico en la Inquisición; destacando que «el tribunal de la Inquisición, el mayor ejemplo de la depravación humana, es un monumento duradero para instruirnos sobre el grado de iniquidad y crueldad al que puede llegar esa depravación cuando se cubre con el sagrado mando de la religión». ${ }^{25}$

\footnotetext{
24 ídem.

25 Por razones de prudencia, y ante la recepción que tuvo su obra, Hume suprimió este pasaje y todo el análisis anterior (que hemos seguido casi textualmente) de las ediciones posteriores de su History; pero puede leerse en Hume 1983: XVII (Foreword by W. B. Todd).
} 
La razón de ese carácter especialmente perverso de la Inquisición se explica en su Historia natural de la religión: se trata de una institución que se centra en la lucha contra la virtud, el saber y el amor a la libertad, cualidades que cuando «son destruidas, dejan a la sociedad en la más vergonzosa ignorancia, corrupción y sometimiento $"{ }^{26}$ Diríamos que esta era la versión más extrema de uno de los bandos en los que iba a dividirse Europa, y es importante tener en cuenta que aunque la perspectiva de participar en el pillaje de la Iglesia hizo que algunos príncipes abrazaran la Reforma, lo cierto es que el catolicismo («the Romish system», escribe Hume) permaneció como la religión favorita de muchos soberanos. El hecho de que inculcara la sumisión ciega de los creyentes, de que rechazara el empleo del juicio privado, de la razón, y de la capacidad propia para investigar las cosas eran tantos a su favor no sólo para la autoridad eclesiástica, sino también para la civil. A ello se unía una cuestión de afinidad de gusto. El esplendor de sus ceremonias resultaba muy agradable al aprecio por la magnificencia que prevalecía en las cortes.

Por el contrario, y pasando al otro bando, de los primeros reformadores que atacaron la superstición romana puede decirse que estaban poseídos del entusiasmo más intenso. De ahí su desprecio hacia ese esplendor de las ceremonias y hacia toda sujeción eclesiástica; y también el carácter intrépido con el que desafiaban los peligros, las torturas, e incluso la muerte misma, mientras -en una contradicción que Hume quiere dejar muy patente- «predicaban la doctrina de la paz y llevaban los tumultos de la guerra a todas las partes del mundo cristiano ${ }^{27}{ }^{27}$

Por muy obstinada y nada favorable al compromiso que fuese esta especie de religión entusiasta, se vio necesariamente alterada según fuera la situación de los asuntos civiles y los diferentes tipos de gobierno que encontró en su progreso. En Alemania, en Dinamarca o en Suecia, donde el monarca se convirtió pronto a los nuevos principios, al ponerse a la cabeza de los reformadores adquirió autoridad sobre ellos y el espíritu entusiasta se vio atemperado por un cierto sentido del orden y por el mantenimiento de determinadas ceremonias. La situación fue muy diferente en Escocia y en los Países Bajos, donde el pueblo inició la reforma en oposición al gobierno establecido. Allí el fanatismo se desarrolló con toda su fuerza. Fueron esos predicadores de los Países Bajos (y de Suiza y Francia) los que llevaron la Reforma a Inglaterra: «Pero como el gobierno era allí monárquico, y el magistrado tomó la iniciativa en esta gran revolución, aunque las doctrinas especulativas fueron tomadas de las iglesias más fanáticas, sin embargo, la disciplina y el culto se atenuaron naturalmente con un espíritu religioso más humano». ${ }^{28}$

No debiéramos extrañarnos entonces de que Hume -en tanto que historiador amigo de las posturas intermediasvalorara muy positivamente el establecimiento de Enrique VIII como «la única cabeza suprema sobre la Tierra de la Iglesia de Inglaterra». A este respecto comentará:

El reconocimiento de la supremacía del rey introdujo allí una mayor sencillez en el gobierno al unir el poder espiritual con el civil, y al evitar disputas sobre

26 Hume 1974: 69.

27 Se trata de otro pasaje de su History, igualmente suprimido, que puede verse en ídem.

28 Ídem. circunscripciones, algo sobre lo que las partes contendientes nunca pudieron llegar a un acuerdo preciso. También se dispuso de un medio para controlar el exceso de la superstición y romper esos grilletes con los que la razón humana, la política y la industria habían estado aprisionadas durante tanto tiempo. Era de suponer que el príncipe, siendo la cabeza tanto de la religión como de la jurisdicción temporal del reino, aunque algunas veces pudiera emplear a la primera como un instrumento de gobierno, no estaba interesado -a diferencia del pontífice romano- en fomentar su crecimiento excesivo; y que, excepto cuando se viera cegado por la ignorancia o el fanatismo, se aseguraría de retener a la religión dentro de unos límites tolerables y de prevenir sus abusos. Y, en conjunto, de esta revolución se siguieron muchas consecuencias beneficiosas, aunque quizás no previstas ni deseadas por las personas que tuvieron la mano principal en dirigirla. ${ }^{29}$

Sin embargo, por mucho que Hume pudiera simpatizar con esta reforma moderada, lo cierto es que, al menos a corto plazo, no funcionó. Dicho más concretamente, no sirvió para limitar o encauzar el entusiasmo que se había despertado. La historia de Inglaterra se iba a deslizar hacia el enfrentamiento y la guerra.

Por una parte tenemos que:

Nada favoreció más los primeros progresos de los reformadores que la libertad que concedían al juicio particular de examinar todas las doctrinas religiosas... Aunque la multitud no estaba en absoluto cualificada para esta empresa, se sentía muy complacida con la misma. Las personas imaginaban que estaban ejerciendo su juicio mientras oponían a los prejuicios de la antigua autoridad prejuicios más poderosos de otra clase. La novedad misma de las doctrinas, el placer de un triunfo imaginario en la disputa, el ferviente celo de los predicadores de la Reforma, la paciencia y aun el júbilo con que sufrían persecuciones, la muerte y torturas; el disgusto ante las restricciones de la antigua religión; la indignación en contra de la tiranía y el espíritu interesado de los eclesiásticos; estos eran los motivos que prevalecían con la gente; y por estas consideraciones eran las gentes inducidas de forma general durante esa época a abandonar la creencia de sus antepasados. ${ }^{30}$

Por otra parte podemos entender perfectamente que Enrique VIII viera esta idea de someter la religión al juicio privado como muy peligrosa. Había que considerar si el deshacerse de la Iglesia católica no podía ser visto por el pueblo como un precedente que preparaba el camino para innovaciones que iban claramente en contra de sus intereses en tanto que monarca dotado de una autoridad absoluta. ¿Qué pensar del "espíritu republicano" de los reformadores? ¿Y del ejemplo de los anabaptistas en Alemania ${ }^{31}$

No debiéramos sorprendernos ante estas amenazas a la autoridad de los monarcas. La Reforma podía ser como un caballo desbocado que no se detiene delante de un precipicio. Pensemos, además, que aunque los teólogos protestantes se habían atrevido a renunciar a opiniones consideradas como ciertas durante mucho tiempo, consideraban a su vez al

29 Hume 1983: III, XXX, 206-7.

30 Ibídem: III, XXXI, 211-212.

31 Véase ídem. Allí Hume también menciona el hecho de que Enrique VIII hubiera combatido en sus escritos las doctrinas de Lutero, al que despreciaba, imaginando que las había refutado. 
nuevo sistema como tan cierto que no estaban dispuestos a permitir ningún intento de contradecir el mismo. Por el contrario, sí estaban bien dispuestos a quemar en las mismas llamas de las que ellos mismos habían escapado por tan poco a todos los que tuvieran el valor de diferir de sus opiniones. ${ }^{32}$

Vamos a asistir entonces a la lucha entre los católicos y los reformistas, y entre las diversas sectas entusiastas que esta actitud produjo. Los reinos de María I de Inglaterra, de Isabel I y la guerra civil inglesa se verán dominados por estos enfrentamientos. Vistos desde una perspectiva secular, como la de Hume, los mismos eran tan estúpidos como trágicos, pero tuvieron una consecuencia política de largo alcance. El espíritu atrevido y osado que acompañaba a estos entusiastas en sus oraciones a la divinidad, aparecía en sus especulaciones políticas:

Y los principios de la libertad civil, que durante algunos reinos habían sido poco reconocidos en la nación; y que eran totalmente incompatibles con las exorbitantes prerrogativas reales del momento, habían sido adoptados con fuerza por esta nueva secta. Apenas ningún soberano antes de Isabel, y ninguno después que ella, llevaron más alto, tanto en la especulación como en la práctica, la autoridad de la corona; y los puritanos (porque así se denominaba a esta secta, en base a su apariencia de una pureza superior de adoración y disciplina) no podían recomendarse a Isabel I de una forma peor que inculcando la doctrina de resistir la autoridad de los príncipes o restringirla. ${ }^{33}$

$\mathrm{Y}$ «fue gracias a esta secta, cuyos principios parecen tan frívolos y cuyos hábitos parecen tan ridículos, que los ingleses deben toda la libertad de su constitución $" .{ }^{34}$ El puritanismo y el amor a la libertad iban a caminar juntos; el noble principio de la libertad se desarrollaría en la generación siguiente a la de Isabel bajo el abrigo de los principios absurdos de los puritanos. ${ }^{35}$ Quien se cree un favorito del cielo tendrá la autoestima y el orgullo suficientes para desconfiar de un monarca si no aprecia en este el respeto a las libertades civiles, y la compañía de Dios que siente en su interior le dará fuerzas y valor para enfrentarse al mismo.

El problema para Hume es que la búsqueda apasionada de la libertad acabó provocando una guerra civil y, paradójicamente, reduciendo a Inglaterra a una situación de esclavitud. ${ }^{36}$ Hume describe así la situación: «Los hipócritas santificados que llamaban a sus opresiones el despojo de los egipcios y a su severidad rígida el dominio de los elegidos, mezclaban todas sus iniquidades con largas y fervientes oraciones, evitaban avergonzarse utilizando gestos piadosos y ejercitaban en el nombre del Señor toda su crueldad sobre los hombres». ${ }^{37} \mathrm{Al}$ fin y al cabo, si el parlamento se había impuesto a la corona, ¿ por qué no iba a imponerse el ejército al parlamento? Las tropas se constituyeron a sí mismas en una especie de república en donde los temas cotidianos de conversación eran los planes para el establecimiento de una nueva forma de Estado. Las propuestas de los niveladores (los Levellers) eran:

32 Véase ibídem: III, XXXIV, 366.

33 Ibídem: IV, XL, 123-124.

34 Ibídem: IV, XL, 146.

35 Véase ibídem: IV, apéndice III, 368. Para este tema de la libertad es interesante acudir a Hicks 2013: 61-79.

36 Véase Hume 1983: V, LIX, 502.

37 Ídem.
Se estaba de acuerdo en abolir la realeza. Los nobles debían ser rechazados. Incluso había que nivelar todas las categorías de hombres e introducir entre los ciudadanos una igualdad universal, tanto de propiedad como de poder. Los santos, decían, eran la sal de la tierra. Una igualdad total tenía lugar entre los elegidos; y por la misma regla que se elevó a los apóstoles desde las profesiones más bajas, el centinela más humilde, si estaba iluminado por el espíritu, tenía derecho a la misma consideración que el comandante más importante. ${ }^{38}$

Por su parte, lo milenaristas o partidarios de la quinta monarquía:

Insistían en que al fundarse la autoridad en la gracia divina, debían abolirse todas las distinciones basadas en las leyes, y sólo permanecer las que surgían de la piedad y la santidad;... esperaban de un momento a otro la segunda venida de Cristo sobre la tierra; y... pretendían que mientras tanto los santos - es decir, ellos mismoseran los únicos que tenían derecho a gobernar. ${ }^{39}$

A su vez, los antinomianos pensaban que «las obligaciones de la moralidad y de la ley natural estaban suspendidas, y que los elegidos, guiados por un principio interno, más perfecto y divino, eran superiores a los elementos miserables de la justicia y la humanidad». ${ }^{40}$

Que para Hume estamos ante una verdadera patología mental que solo podía sumir a Inglaterra en el desorden más extremo se entenderá muy bien si atendemos a su visión general de la sociedad, de lo que constituye la esencia de cualquier sociedad. Los hombres tienen tendencia hacia la parcialidad y el egoísmo, y en tanto que saben que los objetos que satisfacen sus necesidades son escasos (no hay tantas cosas como nuestras aspiraciones puedan desear) es fácil que surjan enfrentamientos entre los mismos sobre la posesión de esos objetos. Al fin y al cabo, lo que le sirve a uno también puede servirle a otro si valiéndose de la fuerza o de la astucia se lo quita al primero. Por eso la sociedad necesita para su misma existencia de leyes de propiedad muy estrictas que determinen con claridad lo que es de cada uno. ${ }^{41}$ Por ejemplo, un objeto será del primero que lo haya encontrado, o los objetos de un padre pasarán al hijo cuando aquél fallezca, etc. Por supuesto, puede haber reglas muy distintas de asignación de propiedad, pero lo mejor es que se basen en el funcionamiento natural de la mente humana, porque así podrá generarse un consenso en torno a las mismas. Resultarán leyes naturales, por mucho que luego necesiten de precisiones que muchas veces serán arbitrarias. Pues bien, una regla de asignación de propiedad que nunca podrá generar consenso, y que por el contrario será fuente de todo tipo de enfrentamientos violentos, es la de dar la propiedad de una cosa al que sea más virtuoso. Y aquí es donde Hume advierte que:

Si la humanidad fuera a poner en práctica tal ley; tan grande es la incertidumbre del mérito de los hombres -tanto por su oscuridad natural como por la presunción de cada individuo-, que de ello no resultaría jamás ninguna regla determinada de conducta; y la

38 Hume 1983: V, LIX, 513; y véase igualmente VI, LX, 3 y 4.

39 Ibídem: VI, LXI, 59.

40 Ibídem: VI, LX, 4.

41 Para el estudio del papel de la propiedad en Hume puede verse Miller 1981: 60-77; y en castellano López Sastre 2002: 125-142. 
total disolución de la sociedad habría de ser la consecuencia inmediata. Los fanáticos pueden suponer que el dominio se funda en la gracia [véase Romanos, 6, 14] y que sólo los santos heredarán la tierra [véase Salmos, $37,29]$, pero el magistrado civil pone muy justamente a estos sublimes teóricos al mismo nivel que los ladrones vulgares; y les enseña, mediante el castigo más severo, que una regla que a nivel especulativo puede parecer la más ventajosa para la sociedad, puede resultar en la práctica, sin embargo, completamente perniciosa y destructiva.

\section{Y para ejemplificar este principio Hume escribe:}

La historia nos enseña que durante las guerras civiles, hubo en Inglaterra fanáticos religiosos de esta clase; aunque es probable que la tendencia natural de estos principios provocase tal horror en la humanidad, que obligara pronto a estos peligrosos entusiastas a renunciar a sus principios, o al menos, a ocultarlos. ${ }^{42}$

El caso de los niveladores no es mejor, pues por plausible que pudiera parecer su propuesta de una distribución igualitaria de la propiedad, de razonable tiene muy poco. Hume está dispuesto a reconocer que "siempre que nos apartamos de la igualdad, robamos al pobre una satisfacción mayor que la que concedemos al rico, y que la gratificación ligera de una vanidad frívola de un individuo frecuentemente cuesta más que el pan de muchas familias», pero observará que la idea de una igualdad perfecta es tan impracticable como perniciosa para la sociedad:

Haced que las posesiones de los hombres sean muy iguales; sus diferentes grados de habilidad, cuidado y aplicación destruirán inmediatamente esa igualdad. 0 , si controláis estas virtudes, reduciréis la sociedad a la indigencia más extrema, y, en vez de evitar la pobreza y la miseria de unos pocos, las haréis inevitables para toda la comunidad..$^{43}$

Vistos por lo tanto lo impracticables por desastrosos que eran los proyectos políticos del entusiasmo más extremo, Hume puede concluir que «su furia es como la del trueno y la tempestad, que se agotan en poco tiempo y dejan el aire más calmado y sereno que antes». ${ }^{44}$ Como prueba de esta tesis asistiremos a una restauración de la monarquía. Es verdad que todavía habrá nuevos enfrentamientos frente a un catolicismo que se percibe como amenaza, y luchas entre episcopalianos y presbiterianos de rígida ortodoxia; pero la revolución de 1688 pondrá fin a este apartado de la historia. La derrota de los jacobitas escoceses en 1745 no será sino la confirmación de esa situación. Escribiendo en un texto pensado para la edición de 1748 de sus Ensayos Hume destaca que en los últimos sesenta años se ha afianzado el parlamento, y que con la libertad pública «han florecido de manera casi constante la paz y el orden internos. Han crecido el comercio, las manufacturas y la agricultura, y se han cultivado las artes, las ciencias y la filosofía. Incluso los partidos religiosos se han visto obligados a dejar de lado su mutuo rencor $»{ }^{45}$

42 Hume 1991: 58-59. Lo que está entre corchetes es un añadido nuestro.

43 Ídem.

44 Hume 2011: 101 («De la superstición y el entusiasmo»).

45 Ibídem: 438 («De la sucesión protestante»). El original inglés pone «religious parties», que nosotros traducimos como «partidos religiosos», alterando así la versión por la que estamos citando, y que pone «partidos políticos».
¿Qué conclusiones generales cabría obtener de toda esta narración y de la conclusión de Hume sobre la afortunada situación del momento? Una primera lección tiene que ver con la importancia de una política de tolerancia. Las persecuciones no sirvieron para nada desde el punto de vista de promover la unidad social. Sólo lograron sumir al país en el enfrentamiento y el caos. Por el contrario, cuando se ha puesto en práctica una política de tolerancia, esta ha mitigado la animosidad de las diversas sectas y el propio dominio de la religión en la vida de las personas y las sociedades. Hume observará que:

Una vez que diferentes sectas se han extendido y arraigado con fuerza, el único recurso que puede mitigar su fervor y conseguir que la unión civil tenga más importancia que las distinciones religiosas es una tolerancia ilimitada. Pero, como los resultados de este procedimiento normalmente son graduales y al principio imperceptibles, los políticos vulgares tienen tendencia, por esta razón, a recurrir a remedios más imprudentes y peligrosos. ${ }^{46}$

Esos remedios peligrosos son los que se pusieron en práctica, pero la experiencia histórica de sus resultados negativos ha hecho que se afiance al fin la opinión contraria: la tolerancia.

Hume pensaba, en efecto, que la herejía (es decir, todo lo que no coincida con las opiniones del grupo religioso dominante) es un crimen que comúnmente aumenta con la represión, y nunca es tan eficazmente suprimido como cuando es totalmente pasado por alto. ${ }^{47}$ Poniendo un ejemplo de este principio Hume habla de que los no conformistas escoceses se sentían completamente superiores a los otros tipos de creyentes y se creían así con el derecho de perseguir a sus adversarios. El problema es que el gobierno, en vez de «tratarlos como locos a los que había que apaciguar, halagar y conducir con algún tipo de engaño a la tranquilidad», consideró que tenía derecho a exigirles obediencia en cuestiones religiosas y se lanzó a reprimirlos. ${ }^{48}$ Sin embargo, las persecuciones resultan fatales a la larga para la paz y el orden social. Las opiniones religiosas presentan la peculiaridad de que se fortalecen con los castigos que amenazan a quienes las sostienen. El celo religioso se inflama por momentos y acaba oponiéndose tan directa como vigorosamente a este gobierno que busca reprimirlo. Por el contrario, una política de tolerancia acaba apaciguando la furia del fervor religioso y consiguiendo que predomine el sentido de la unidad civil. Esto es lo que, como cuestión de hecho, probó el ejemplo de las Provincias Unidas, en donde se ha comprobado que diferentes sectas religiosas pueden vivir en paz y armonía, y tener todas ellas el mismo afecto a su país común. A este respecto Hume comentará con aprobación:

Los holandeses comenzaban a preocuparse más del comercio que de la ortodoxia; y pensaban que el dominio de las artes útiles y la obediencia a las leyes formaban un buen ciudadano; aunque estuviera acompañado de errores en temas donde no es permisible para la naturaleza humana esperar obtener alguna verdad o certeza positiva. ${ }^{49}$

46 Hume 1983: VI, LXVI, 322

47 Véase ibídem: IV, XXXIX, 62.

48 Véase ibídem: VI, LXVI, 322.

49 Ibídem: V, LII, 242. En la Historia natural de la religión Hume escribe que «si entre los cristianos, ingleses y holandeses han abrazado 
Tendríamos aquí una especie de justificación pragmática, o «realista» de la tolerancia religiosa. Puesto que las creencias religiosas existen (nos guste o no, y ya sabemos que a Hume le provocaban un profundo disgusto, tanto porque eran irracionales como por sus consecuencias sociales), lo mejor es apaciguarlas y volverlas tan inofensivas como se pudiera; y para ello el mejor mecanismo es precisamente la tolerancia. Nada de persecuciones por parte del Estado. Mucho mejor una indiferencia que logre que al final termine prevaleciendo el interés por los asuntos y placeres de esta vida. Como Hume concluye:

La misma persona que en otras circunstancias hubiera desafiado a las llamas y a la tortura se ve inducida a cambiar de secta por la perspectiva más pequeña de obtener algún favor o lograr algún progreso social, o incluso por la esperanza frívola de estar más a la moda en sus principios. ${ }^{50}$

Hume propone además un segundo recurso para debilitar las creencias religiosas y volverlas inofensivas, el control estatal de la Iglesia. Por eso, como hemos visto, aprobaba la actuación de Enrique VIII. Convirtiendo esta actitud en un principio general va a declarar que en toda sociedad han de distinguirse dos tipos completamente diferentes de profesiones: en primer lugar, aquellas que, al mismo tiempo que promueven los

los principios de la tolerancia, este singular hecho se debe a la firme resolución de los magistrados civiles, en oposición a los persistentes esfuerzos de sacerdotes y fanáticos». Hume 1974: 68. Tenemos aquí dos tesis importantes. En primer lugar, que una política de tolerancia es algo "singular», no lo normal. Y como segunda tesis que es una decisión de los magistrados civiles. El cristianismo (o cualquier otra religión monoteísta) no produce la tolerancia a partir de sus propios principios. Se tiene la sospecha de que no es que los cristianos no sean tolerantes porque en realidad no son buenos cristianos. No es que no comprendan su propia religión, que en su verdadera esencia sería tolerante. Aunque es verdad que ha habido cristianos tolerantes. Hume menciona, contraponiéndolos a los católicos y a los presbiterianos, a la secta de los independientes durante la guerra civil inglesa: «De todas las sectas cristianas, esta fue la primera que durante su prosperidad, igual que durante su adversidad, siempre adoptó el principio de la tolerancia». Hume 1983: V, LVII, 443. Para él, la mente de estos entusiastas, flotando en el ancho mar de la inspiración no podía ponerse ningún límite, estaban dispuestos a conceder a otros creyentes las mismas diferencias que se permitían a sí mismos. Pero esto es la excepción. Concluyendo, si la intolerancia es el resultado natural del cristianismo, la tolerancia sólo puede ser el resultado de la secularización, de magistrados que ponen en práctica una política en la que predominan los intereses temporales de la sociedad. Esto no es difícil, porque estos intereses, como vamos a ver más adelante, predominan normalmente.

50 Hume 1983: III, XXXVII, 433. Es verdad que una política de tolerancia es extremadamente beneficiosa para los intereses de la sociedad, pero Hume también habría pensado que la defensa de la tolerancia es una cuestión de principios. Por eso se distancia de la propuesta de Montesquieu en L'Esprit des Loix de que cuando los magistrados están satisfechos con la religión establecida deben reprimir los primeros desarrollos de nuevas tendencias; quedando restringida la tolerancia, por consiguiente, a los grupos que estén fuertemente asentados. Hume observa ante esta propuesta que él cree, por el contrario, que es muy cuestionable que las persecuciones puedan justificarse en algún caso. También notará (de una forma tan maliciosa como irónica) que la idea de que no hay que ser tolerantes con las nuevas sectas que pueden ser erradicadas fácilmente envuelve una cierta justificación de las antiguas persecuciones religiosas contra el cristianismo que realizaron los paganos, o del intento de extirpar el mismo en China y Japón, "y en base a esta consecuencia detestable debería seguramente enterrarse en un olvido y silencio eterno». Hume 1983: III, XXXVII, 433; y véase para la crítica a Montesquieu ibídem: V, LVII, note FF, 575-576. intereses de la sociedad, resultan también útiles o agradables para quienes las desempeñan. Es el caso, por ejemplo, de los médicos o los artesanos. El desarrollo de este tipo de actividades ha de confiarse a las personas que logran algún beneficio de las mismas. Es decir, al libre mercado. Quienes ejercen estas profesiones, al observar que sus ganancias dependen del favor del público, ya se preocuparán en función de su propio interés en mejorar su habilidad e industria. Estamos, por tanto, ante un ámbito en donde el Estado no ha de intervenir para nada. Excepto quizá - matizará Hume- en la primera introducción de cualquier arte.

Pero en segundo lugar hay profesiones que, aunque son útiles e incluso necesarias para la comunidad, no proporcionan ninguna ventaja particular a quienes las desempeñan. Aquí el Estado ha de ocuparse de ellas. El ejército, la marina, la magistratura y la hacienda pública serían buenos ejemplos de este tipo de ocupaciones.

Pues bien, ¿en qué categoría debiéramos colocar a la profesión eclesiástica? He aquí la respuesta de Hume:

Podría pensarse a primera vista que los eclesiásticos pertenecen a la primera clase, y que su estímulo -igual que el de abogados y médicos - puede confiarse con seguridad a la liberalidad de los individuos que se adhieren a sus doctrinas y que se benefician o encuentran consuelo en su ministerio y asistencia espiritual. Su actividad y su diligencia, sin duda, se verán incitadas por tal motivo adicional; y su habilidad en la profesión, igual que su destreza en gobernar las mentes del pueblo, recibirá un incremento continuo por su creciente práctica, estudio y atención. / Pero si consideramos más detenidamente este asunto, encontraremos que esta interesada diligencia del clero es lo que todo legislador prudente tratará de impedir;... Cada profesional de los fantasmas, con vistas a convertirse en más valioso y sagrado a los ojos de sus partidarios, les inspirará con el aborrecimiento más violento hacia las otras sectas, e intentará continuamente excitar con alguna novedad la languideciente devoción de su auditorio. No se prestará ninguna consideración a la verdad, la moral o la decencia en las doctrinas inculcadas. Se adoptarán los dogmas que sirvan mejor a los afectos desordenados de la naturaleza humana. Se atraerán clientes a cada conventículo mediante la utilización de nuevos trabajos y destrezas que operen sobre las pasiones y credulidad del vulgo. Y, al final, el magistrado civil encontrará que ha pagado cara su supuesta frugalidad al ahorrarse una cantidad fija destinada a los clérigos; y que en realidad el acuerdo más ventajoso y decente al que puede llegar con los guías espirituales es comprar su indolencia asignando un salario establecido a su profesión, y convirtiendo así en superfluo para ellos el estar más activos que lo meramente necesario para evitar que su rebaño se extravíe en busca de nuevos pastos. ${ }^{51}$

51 Hume 1983: III, XXIX, 135-136. Hume no se ha ocupado del efecto que tendría la política de tolerancia que defiende sobre el predominio de esa Iglesia que podemos llamar «oficial». Aunque cabe asumir, como muy bien ha sugerido J. B. Stewart, que pensaría que dada una Iglesia estatal bien dirigida y alejada de toda compulsión y fanatismo no habría, como cuestión de hecho, un gran deseo de alternativas. Véase Stewart 1973: 284. Es verdad que siempre podrían desarrollarse otras religiones - por ejemplo, aquellas primariamente relacionadas con la influencia cultural de otros países - o crearse nuevas sectas o grupos disidentes producto del predomino en la sociedad del propio espíritu de libertad, pero no parece que pudieran alcanzar una fuerza y una influencia tales que llegaran a poner en cuestión el carácter tan hegemónico como especial de esa Iglesia sustentada por el poder político. Otra cosa 
Esta tesis de que el poder civil ha de controlar al clero aparece igualmente en el ensayo "Idea de una república perfecta» en donde Hume propone el que cree que sería el mejor sistema de gobierno..$^{52}$ Allí defiende una república en donde unos votantes económicamente cualificados escogen e unos representantes que, a su vez, eligen de entre ellos a un conjunto de magistrados o senadores. Y en cuanto al sistema eclesiástico de esta república, Hume propone lo siguiente:

Los magistrados nombran rectores o ministros en todas las parroquias. / Se establece el sistema de gobierno presbiteriano, y la corte suprema eclesiástica es una asamblea o sínodo de todos los presbíteros del país. Los magistrados pueden hacerse cargo de cualquier causa de esta corte y ser ellos quienes decidan. / Los magistrados pueden juzgar y deponer o suspender a cualquier presbítero. ${ }^{53}$

Esta era la postura que siempre había defendido en su Historia. Citemos un último texto de esta obra:

La unión de los poderes eclesiástico y civil sirve muy bien, en todo gobierno civilizado, para el mantenimiento de la paz y el orden; y previene esas usurpaciones mutuas que, como no puede haber un juez último sobre las mismas, se ven acompañadas a menudo de las consecuencias más peligrosas. $\mathrm{Si}$ el magistrado supremo, que une a ambos poderes, recibe el nombre de príncipe o prelado no es importante. El peso superior que los intereses temporales tienen normalmente en las preocupaciones de las personas sobre los espirituales, hace que la parte civil de su carácter prevalezca más. ${ }^{54}$

es la credibilidad que tuviera la misma en una sociedad donde la opinión pública sea consciente de la intención de sus gobernantes. Pero aquí hay que decir que Hume estaba pensando en su época y en la forma de salir de los atolladeros de un siglo de enfrentamientos religiosos, no intentando legislar de forma universal para la posteridad. Quizá por esto lo que propone en los Diálogos es diferente. Filón manifiesta que a lo más que puede aspirar un magistrado prudente es a convertir a la religión en "un juego sin riesgos» y "prevenir sus perniciosas consecuencias con respecto a la sociedad». Algo que reconoce que es una tarea difícil: si sólo admite una única religión entre el pueblo, «debe sacrificar en aras de una perspectiva incierta de tranquilidad toda consideración hacia la libertad pública, la ciencia, la razón, la industria... » Excluida entonces esta posibilidad, queda otra opción hipotética: «si autoriza varias sectas, lo cual constituye la medida más prudente, debe mantener una indiferencia muy filosófica con respecto a todas ellas, y restringir cuidadosamente las pretensiones de la secta predominante, de lo contrario sólo podrá esperar disputas interminables, peleas, banderías, persecuciones y conmociones civiles». Hume 1974: 190 (hemos modificado en algo la traducción; y así traducimos «uncertain» por «incierta»). Lo interesante de esta propuesta es que no es necesario que el Estado controle una Iglesia, basta que sea indiferente hacia todas ellas y no les deje traspasar determinados límites, por ejemplo - se nos ocurre pensar- evitando que su concepción de lo que es un «pecado» se convierta en un «delito».

52 Se ha discutido mucho sobre si este ensayo ha de tomarse en serio o si se trata de un mero divertimento. Véase Stewart 1992: 282, nota 38. Pero en lo referente a sus propuestas de política eclesiástica no puede haber ninguna duda de su seriedad, porque coinciden plenamente con el conjunto de los planteamientos de Hume.

53 Hume 2011: 449. La última frase que hemos citado no figura en esta traducción. Cfr. el original en Hume 1985: 520. Una vez que se restableció el patronazgo en Escocia (los patrones laicos, incluyendo de una forma predominante a la Corona, nombraban los ministros de las parroquias de sus propiedades) el sistema propuesto por Hume no era muy diferente de lo que allí ocurría.

54 Hume 1983: I, VIII, 311.
Las últimas palabras son la clave de toda su propuesta. Se trata de que tras un velo religioso prevalezcan los intereses de esta vida, la prosperidad y la felicidad de las personas. Lo cierto es que nuestro autor pensaba que, a pesar del estilo imperioso y dogmático que adoptan todas las creencias religiosas, estas son muchas veces más aparentes que reales y casi nunca logran alcanzar la solidez y la persuasión que son propias de las creencias que gobiernan los asuntos cotidianos. Así, en el Tratado de la naturaleza humana, la obra con la que comenzábamos nuestra exposición, va a subrayar que los más sensatos de los católicos, "la más fanática de las sectas del mundo cristiano», censuran el complot de la pólvora para volar el parlamento inglés en 1605 o la matanza de San Bartolomé de 1572 como actos crueles y bárbaros, aunque estaban proyectados y ejecutados «contra esas mismas personas a las que, sin escrúpulo ninguno, condenan a castigos eternos e infinitos. Todo lo que podemos decir para excusar esta inconsistencia es que no creen realmente lo que afirman concerniente a la vida futura, y no existe una prueba mejor de ello que su misma inconsistencia ». ${ }^{55}$

Si es verdad que sólo en circunstancias muy determinadas adquiere la religión el poder de contraponerse con fuerza a los intereses de esta vida, será muy importante evitar las mismas. El contexto adecuado para que la religión no cause destrozos en la vida social es que a la gente se la deje en paz y se toleran sus opiniones religiosas, que la propia Iglesia - que para eso está controlada por el Estado- vigile que no haya contraposición entre los intereses religiosos (cualquier cosa que signifique esto) y los temporales. En esta situación las creencias religiosas van perdiendo importancia frente a los placeres y las preocupaciones del aquí y ahora. Al fin y al cabo sabemos que las ideas religiosas no tienen apoyo en la experiencia. Dejemos, por tanto, que el hombre religioso afirme lo que en el fondo muchas veces no cree. Demos la bienvenida a una inconsistencia como la de los católicos en el texto que acabamos de citar. El resultado de la política propuesta es que podía decirse de una manera que sonaba plausible que:

En estos últimos cincuenta años, ha habido un súbito y perceptible cambio en las opiniones de la gente, debido al progreso en el aprendizaje y a la libertad. La mayoría de la gente, en esta isla, se ha liberado de toda veneración supersticiosa por los nombres y la autoridad. El clero ha perdido gran parte de su prestigio. Se han ridiculizado sus pretensiones y sus doctrinas, e incluso apenas puede la religión seguirse sosteniendo en el mundo. 56

Lo cierto es que el espíritu de la libertad civil, aunque inicialmente hubiera estado unido al entusiasmo religioso, puede «purgarse de esa contaminación» (las palabras son de Hume) y presentarse bajo un aspecto más atractivo, como "amigo de la tolerancia y promotor de los sentimientos agrandados y generosos que honran a la humana naturaleza». ${ }^{57}$ Que las tormentas de la Reforma protestante hubieran llevado a través de muchas vueltas a una situación

55 Hume 2012: 110.

56 Hume 2011: 81 («De si el Gobierno británico se inclina más hacia la monarquía absoluta o hacia una república»).

57 Hume 2011: 433 («De la coalición de partidos»). 
que pudiera describirse así (aunque de una manera que creemos exagerada en cuanto al desprestigio social de la religión en la Gran Bretaña del momento), parecería validar una cierta ley histórica que vamos a expresar con las famosas palabras de Cromwell: ningún hombre llega tan arriba como aquél que no sabe a dónde se dirige. ${ }^{58}$ Lo que por supuesto no dice nada en contra de que nos esforcemos en preservar conscientemente lo que nuestros antepasados ni preveían ni deseaban. Esta era la postura de Hume.

\section{BiBLIOGRAFÍA}

Carabelli, G. 1972. Hume e la retorica dell'ideologia. Uno studio de "Dialoghi sulla religione naturale». Firenze: La nuova Italia Editrice.

Forbes, D. 1975. Hume's Philosophical Politics. Cambridge: Cambridge University Press.

Gaskin, J. C. A. 1988. Hume's Philosophy of Religion. Londres: Macmillan.

Harris, J. A. 2015. Hume. An Intellectual Biography. Cambridge: Cambridge University Press.

Hicks, P. 2013. "'The Spirit of Liberty': Historical Causation and Political Rhetoric in the Age of Hume», en M. G. Spencer (ed.), David Hume. Historical Thinker, Historical Writer: 61-79 Pennsylvania: The Pennsylvania State University Press.

Hume, D. 1974. Historia natural de la religión. Diálogos sobre la religión natural. Salamanca: Ediciones Sígueme. [Prólogo a la edición castellana de J. Sádaba. Traducciones de A. J. Cappelletti, H. López y M. A. Quintanilla].

Hume, D. 1983. The History of England from the Invasion of Julius Caesar to the Revolution of 1688. Indianápolis: LibertyClassics. VI vols.

Hume, D. 1985. Essays Moral, Political and Literary. Indianápolis: LibertyClassics. [Edited and with a Foreword, Notes and Glossary by E. F. Miller].

Hume, D. 1991. Investigación sobre los principios de la moral. Madrid: Espasa Calpe. [Edición y traducción de G. López Sastre].

Hume, D. 2004. Investigación sobre el entendimiento humano. Madrid: Ediciones Istmo. [Edición bilingüe. Traducción de V. Sanfélix Vidarte y C. Ors Marqués. Introducción, notas y comentarios de V. Sanfélix Vidarte. Epílogo de B. Stroud].
Hume, D. 2011. Ensayos morales, políticos y literarios. Madrid: Editorial Trotta y Liberty Fund. [Edición, prólogo y notas de E. F. Miller. Traducción de C. Martín Ramírez].

Hume, D. 2012. Tratado de la naturaleza humana. Madrid: Gredos. [Estudio introductorio por J. L. Tasset].

Le Jallé, É. 2008: «Enthousiasme et superstition à partir de l'Histoire d'Angleterre de Hume». Revue de métaphysique et de morale 59 (3): 351-363.

López Sastre, G. 1994. «David Hume, o la reflexión escéptica sobre el mundo religioso», en M. Fraijó (ed.), Filosofía de la religión. Estudios y textos: 159-177. Madrid: Ed. Trotta.

López Sastre, G. 2002. "Sobre la posibilidad y el contenido de la filosofía política y moral en el pensamiento de David Hume», en A. Domínguez Basalo (coord.), Vida, pasión y razón en grandes filósofos: 125-142. Cuenca: Ed. de la Universidad de Castilla-La Mancha.

López Sastre, G. 2011a. «Creencias religiosas superficiales, clérigos hipócritas y control secular de la Iglesia. Tres elementos del pensamiento de Hume». Daimon. Revista Internacional de Filosofía 52: 173-188. [Número monográfico «David Hume: en el tercer centenario de su nacimiento»].

López Sastre, G. 2011b. «Más allá de la tolerancia. De la Ilustración al romanticismo», en M.a J. Villaverde Rico y J. C. Laursen (eds.), Forjadores de la tolerancia: 304-322. Madrid: Ed. Tecnos.

López Sastre, G. 2012. «David Hume on Religious Tolerance», en M. a J. Villaverde Rico y J. C. Laursen (eds.), Paradoxes of Religious Toleration in Early Modern Political Thought: 139-157. Lanham: Lexington Books.

Miller, D. 1981. Philosophy and Ideology in Hume's Political Thought. Oxford: Clarendon Press.

Mossner, E. C. 1980. The Life of David Hume. Oxford: Oxford University Press.

Norton, D. F. (ed.) 1993. The Cambridge Companion to Hume. Cambridge: Cambridge University Press.

Phillipson, N. 1989. Hume. London: Weidenfeld and Nicolson.

Stewart, J. B. 1973. The Moral and Political Philosophy of David Hume. Westport (Connecticut): Greenwood Press.

Stewart, J. B. 1992. Opinion and Reform in Hume's Political Philosophy. Princeton: Princeton University Press.

58 Coincidimos aquí con la opinión de Le Jallé cuando habla de que en relación a la defensa de la libertad civil por las sectas entusiastas puede pensarse en la fórmula famosa de Hayek: «producto de la acción de los hombres, pero no de su diseño». Ver la página 362 de su artículo mencionado en la nota 15 